$\S=-1$

\title{
The Peseudo-Static Displacement Calculation of Reinforced and Unreinforced Soil Walls in Frictional Cohesive Soils Using Horizontal Slices Method
}

\author{
${ }^{1}$ Mojtaba Ahmadabadi, 1Maryam Bahrami, 1Zari Taheri, 1Samaneh Mardani \\ 1Shiraz Art Institute of Higher Education, Shiraz, Iran
}

\begin{abstract}
Horizontal slices method is a simple and efficient tool for analysis of retaining walls. In this paper, using some of the principles of equilibrium and horizontal slices method, an analytical approach is presented to determine the displacement of concrete walls in the reinforced and unreinforced soils. The formulation of the so-called method is able to calculate wall displacement and critical wedge angle displacement for frictional cohesive soils and draw the distribution of displacement in the wall height. Based on the proposed method, a simple equation is presented to calculate the wedge angle of rupture in the frictional cohesive soils in seismic condition. Comparison of the results with previous methods and numerical methods shows that horizontal slices are able to analyze the concrete wall displacement, while the proposed method has the advantage of analyzing walls via considering soil parameters such as adhesion, seismic coefficients, and the number of reinforcements. In contrast with previous methods that ignored the cohesion concrete wall characteristics, the offered method considers all wall and soil parameters. In addition, design charts are presented for different soils and walls. Considering wall displacement, maximum displacement of wall, displacement of wall apex, and maximum place of wall displacement are obtained, revealing that critical wedge angle displacement is different from rupture wedge angle of pressure imposed on wall.
\end{abstract}

Keywords: retaining wall, horizontal slices method, reinforced soil slopes, cohesive frictional soil, wedge failure angle.

\section{Introduction}

Wall displacement calculation is a critical issue in geotechnical engineering and soil and wall interaction. Assuming the issues related to retaining wall, two basic issues of wall analysis and its designing are generally important. The former is related to geotechnical issues and the latter is the number of structural issues. As the process of analysis and determination of the degree of displacement is more precise, designing holder structures is more efficient and economical. Therefore, analysis issues are the most important holder structure issues. Development of reinforcements and their significant impact in reducing displacement demonstrate the need to calculate the reinforcements' force in cohesive frictional soils with seismic effect. To study the deformation of walls and reinforced roofs, there are three study methods: laboratory, numerical, and analytical. Vagneron and Adams (1973) provided the first experimental results for the analysis of displacement on reinforced soil walls. Sakaguchi (1996) examined the reinforced wall with a light block surface under shake-table testing and centrifuge. Sabermahani et al. (2008) conducted 20 tests on reinforced soil walls using shaking table test. They examined the impact of parameters such as soil density, length of reinforcements, hardness, and distances of reinforcements on seismic response of reinforced soil walls. Bourgieos et al. (2011) studied the displacement of various models using numerical analysis of finite element for three-dimensional and flat strain modes. Athanasopoulos et al. (2012) using numerical modeling with two-dimensional finite element PLAXIS software studied seismic response of two retaining walls under seismic loads. Richards and Elms (1979) presented an analytical method to determine the displacement of rigid retaining walls based on Newmark method. Using Richards and Elms (1979) method involves determining the rupture acceleration for soil and wall system. Mojallaland and Ghanbari (2012) proposed a formulation to calculate permanent displacement of weight retaining wall at unreinforced soil state based on kinematic limit analytical method. In recent years, to study the effect of horizontal reinforcements, a method called horizontal slices was presented by researchers at Tehran University (Fakher et al. 2002). The idea of this method was raised out firstly by Shahgholi et al. (2001), and then it was expanded by Nouri et al. (2006), Azad et al (2008), and Reddy et al. (2008). In Ahmadabadi and Ghanbari (2009) method for reinforced walls, a method was presented in order to calculate reinforcements forces based on 5n unknowns and $5 \mathrm{n}$ equations for frictional cohesive soils. In general, the presented analytical method is able to calculate the active pressure of soil, tensile strength of reinforcements, and wedge angle of rupture for reinforced walls in frictional cohesive soils. Ghanbari and Ahmadabadi (2010a, b) provided a formulation in terms of pseudo-static and pseudo-dynamic states for oblique walls for calculating the pressure exerted on it. The results show that, contrary to what is seen in vertical walls, the distribution of soil active pressure on oblique walls follows a non-linear curve, and therefore the effect point of the resultant pressure force on the wall is less than one-third of the wall height from the wall base.

Using horizontal slices method, Ghanbari et al. (2013) presented a new formulation to estimate the acceleration the seismic displacement of reinforced soil slopes. The conducted analysis has been provided for agricultural soil (conditions of $c=0$ ) without the effect of vertical acceleration of earthquake. Gao et al. (2014), using the horizontal slices method, studied the rupture and reinforcement forces in the soil behind the wall. The analyses have 
been carried out for non-cohesive soils and quasi-static state. Lin et al. (2015) examined live loads impact on cohesive frictional walls. The presented method is in quasi-static mode and unreinforced soil. Considering the ongoing seismic displacement of concrete reinforced walls, no complete formulation has been provided for reinforced cohesive frictional soil.

The applied method in this study took advantage of analytical solution based on horizontal slices method and limit equilibrium principles.

Specific innovation of this study is to present a solution to express reinforcement forces and displacement distribution of walls with pseudo-static frictional soils. Other objectives of this study are to study maximum displacement and draw displacement modes and determine critical rupture wedge angle with displacement priority. An advantage of this method is taking into account parameters such as cohesion and friction angle between soil and wall and internal friction angle of soil. It also considers different parameters of wall such as concrete hardness and elasticity modulus of concrete, the effect of concrete cracking, wall thickness, and steel reinforcement characteristics. Behavioral model of wall can be elastic and elasto-plastic depending on dimensions of the wall.

\begin{tabular}{|c|c|c|c|}
\hline & Nomenclature & & \\
\hline $\mathrm{A}_{\mathrm{i}}$ & area of ith slice & $\mathrm{Ui}$ & $\begin{array}{c}\text { coefficients } \\
\text { dependent } \\
\text { upon XVi } \\
\text { and hi }\end{array}$ \\
\hline $\mathrm{c}$ & cohesion of soil $(\mathrm{kPa})$ & $\mathrm{Ui}+1$ & $\begin{array}{c}\text { coefficients } \\
\text { dependent } \\
\text { upon XVip1 } \\
\text { and hi }\end{array}$ \\
\hline $\mathrm{y}$ & $\begin{array}{l}\text { Displacement top of the } \\
\text { wall }(\mathrm{mm})\end{array}$ & Wi & $\begin{array}{l}\text { weight of ith } \\
\text { slice }(\mathrm{kN})\end{array}$ \\
\hline hi & height of ith slice (m) & XVip1 & $\begin{array}{l}\text { horizontal } \\
\text { distance of } \\
\text { Vip1 from } \\
\text { wall }(\mathrm{m})\end{array}$ \\
\hline $\mathrm{H}$ & height of wall (m) & XGi & $\begin{array}{c}\text { horizontal } \\
\text { distance of } \\
\text { Wi from wall } \\
(\mathrm{m})\end{array}$ \\
\hline $\mathrm{H}_{\mathrm{i}+1}$ & $\begin{array}{l}\text { horizontal force at bottom } \\
\text { of ith slice }(\mathrm{kN})\end{array}$ & $\mathrm{XVi}$ & $\begin{array}{c}\text { horizontal } \\
\text { distance of } \\
\text { Vi from wall } \\
\text { (m) }\end{array}$ \\
\hline $\mathrm{H}_{\mathrm{i}}$ & $\begin{array}{c}\text { horizontal force at top of } \\
\text { ith slice }(\mathrm{kN})\end{array}$ & $\mathrm{y}_{1}$ & $\begin{array}{l}\text { Instantaneous } \\
\text { Deflection }\end{array}$ \\
\hline $\mathrm{kh}$ & $\begin{array}{l}\text { Horizontal seismic coeffi- } \\
\text { cient(dimensionles) }\end{array}$ & $\mathrm{y}_{2}$ & $\begin{array}{l}\text { Long-term } \\
\text { Deflection }\end{array}$ \\
\hline $\mathrm{E}_{\mathrm{c}}$ & $\begin{array}{l}\text { Modulus of elasticity of } \\
\text { concrete }\end{array}$ & $\mathrm{Vi}+1$ & $\begin{array}{l}\text { normal force } \\
\text { at bottom of } \\
\text { ith slice }(\mathrm{kN})\end{array}$ \\
\hline $\mathrm{E}_{\mathrm{s}}$ & $\begin{array}{l}\text { Modulus of elasticity of } \\
\text { steel }\end{array}$ & $\mathrm{Vi}$ & $\begin{array}{l}\text { normal force } \\
\text { at top of ith } \\
\text { slice }(\mathrm{kN})\end{array}$ \\
\hline $\mathrm{I}_{\mathrm{g}}$ & Moment of inertia Elastic & $\square \square$ & $\begin{array}{c}\text { inclination } \\
\text { angle of } \\
\text { backfill soil } \\
\left({ }^{\circ}\right)\end{array}$ \\
\hline $\mathrm{I}_{\mathrm{ep}}$ & $\begin{array}{l}\text { Moment of inertia elasto } \\
\text { plastic }\end{array}$ & & \\
\hline \multirow[t]{2}{*}{$\mathrm{Ni}$} & $\begin{array}{l}\text { normal force on failure } \\
\text { surface for ith slice }(\mathrm{kN})\end{array}$ & & \\
\hline & $\mathrm{Si}$ & $\begin{array}{c}\text { shear } \\
\text { force } \\
\text { on } \\
\text { failure } \\
\text { surface } \\
\text { for ith } \\
\text { slice } \\
(\mathrm{kN}) \\
\end{array}$ & Greek letters \\
\hline & tensile f & 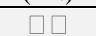 & \\
\hline
\end{tabular}

\begin{tabular}{|c|c|c|c|}
\hline & forcements (kN) & $\begin{array}{c}\text { failure sur- } \\
\text { face to hori- } \\
\text { zontal plane } \\
\left({ }^{\circ}\right)\end{array}$ \\
\hline $\mathrm{A}_{\mathrm{s}}$ & The cross section of steel & $\square$ & $\begin{array}{c}\text { total unit } \\
\text { weight } \\
(\mathrm{kN} / \mathrm{m} 3)\end{array}$ \\
\hline $\mathrm{kv}$ & $\begin{array}{c}\text { Vertical seismic coeffi- } \\
\text { cient(dimensionless) }\end{array}$ & $\square \square$ & $\begin{array}{c}\text { friction angle } \\
\text { between wall } \\
\text { and backfill } \\
\text { soil }(\square)\end{array}$ \\
\hline $\mathrm{Sv}$ & $\begin{array}{c}\text { vertical spacing of rein- } \\
\text { forcements (m) }\end{array}$ & $\square \square$ & $\begin{array}{c}\text { angle of } \\
\text { internal } \\
\text { friction of } \\
\text { soil ( } \square)\end{array}$ \\
\hline $\mathrm{d}$ & Wall thickness(mm) & & \multicolumn{2}{|c|}{} \\
\hline
\end{tabular}

\section{The Proposed Method to Determine Dis- placement of Retaining Wall in the Unrein- forced Soil:}

The proposed method to determine displacement of retaining wall in the unreinforced soil:

As walls, based on the hypothesis, are long, and the deformation can be ignored in longitudinal direction, we can look at the problem as plane strain. We consider the wall as a bending beam. Bending beam assumption has been previously used on littoral shields and piles (Matlock and Reese, 1960); the assumption is acceptable considering retaining walls behavior. Figure 1 shows a retaining wall behind which the soil is divided into horizontal components, and rupture wedge makes angle $\square$ with vertical axis. Forces acting on slice $\mathrm{i}$ of the wall displace each piece in the wall. |Hypotheses

1. Rupture surface has been considered as plane.

2. The analysis is based on limit equilibrium method.

3. The rupture level passes over the wall base.

4. The $\mathrm{N}$ force effect is from the bottom of slice.

5. Soil mass is considered homogeneous.

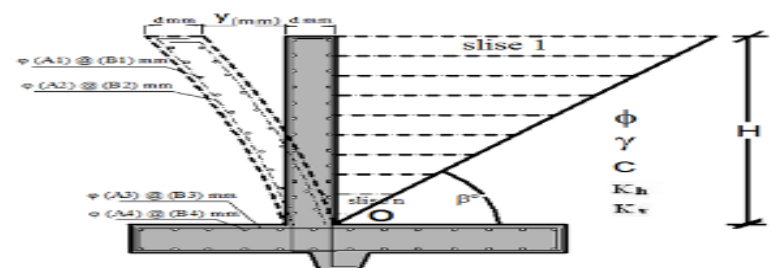

Figure 1: Overall displacement of reinforced concrete wall under lateral force $\mathrm{P}$

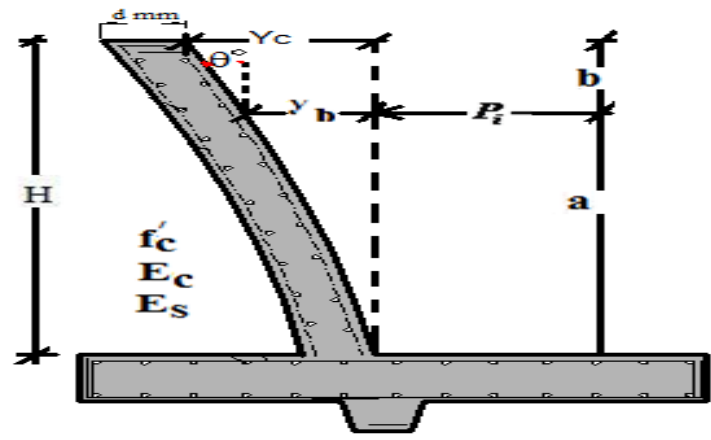

Figure 2: Wall displacement under lateral force $\mathrm{P}_{\mathrm{i}}$

Force $P_{i}$ is calculated for each slice (based on Table 1 or 2) given the reinforced and unreinforced soil condition and we give effect to center of slice $i$. 
Table 1: Number of equations and unknowns in the horizontal slices method in unreinforced soil

\begin{tabular}{|c|c|c|c|}
\hline Unknowns & Number & Equations & Number \\
\hline $\begin{array}{c}H_{i} \\
\text { Inter-slice shear force }\end{array}$ & $n$ & $\sum_{\text {For each slice }} F_{x}=0$ & $n$ \\
\hline $\begin{array}{c}N_{i} \\
\text { Normal forces at base of } \\
\text { each slice }\end{array}$ & $n$ & $\sum_{\text {For each slice }} F_{y}=0$ & $n$ \\
\hline $\begin{array}{c}S_{i} \\
\text { Shearforces at base of } \\
\text { each slice }\end{array}$ & $n$ & $\begin{array}{l}\sum M_{o}=0 \\
\text { For each slice }\end{array}$ & $n$ \\
\hline $\begin{array}{c}P_{i} \\
\text { Net force on wall }\end{array}$ & $n$ & $\begin{array}{c}S i=N_{i}(\tan \square \square+C \\
\text { For each slice }\end{array}$ & $n$ \\
\hline - & $4 n$ & 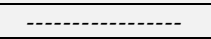 & $4 n$ \\
\hline
\end{tabular}

Table 2: Number of equations and unknowns in the horizontal slices method when in reinforced soil

\begin{tabular}{|c|c|c|c|}
\hline Unknowns & Number & Equations & Number \\
\hline $\begin{array}{c}H_{i} \\
\text { Inter-slice shear force }\end{array}$ & $n$ & $\begin{array}{c}\sum F_{x}=0 \\
\text { For each slice }\end{array}$ & $n$ \\
\hline $\begin{array}{c}N_{i} \\
\text { Normal force at base } \\
\text { of each slice }\end{array}$ & $n$ & $\begin{array}{c}\sum F_{y}=0 \\
\text { For each slice }\end{array}$ & $n$ \\
\hline $\begin{array}{c}\text { Shear force at base of } \\
\text { each slice }\end{array}$ & $n$ & $\sum M_{o}=0$ & $n$ \\
\hline$T_{i}$ & For each slice & $n$ \\
\hline$P_{i}$ & $n$ & $\begin{array}{c}\text { Fi= } N_{i}(\tan \square \square \square+ \\
\text { For each slice }\end{array}$ & $n$ \\
\hline Net pressure on wall & & $\begin{array}{c}\tau_{m}=\lambda\left(\tau_{f}\right) \\
\text { For each slice }\end{array}$ & $n$ \\
\hline ----------------- & $5 n$ & ----------- & $5 n$ \\
\hline
\end{tabular}

Depending on the number of slices (n), $P_{i}$ force is exerted on wall. Due to the force exerted by each slice, a displacement is created on the top of the wall which is calculated based on equation 1:

$$
y_{C}=y_{b}-b O_{b}
$$

To determine the slope and displacement of wall, second order linear differential equations of 2 to 4 are used.

$$
\begin{aligned}
& \frac{d^{2} y}{d h^{2}}=\frac{M(h)}{E I} \\
& E I \frac{d y}{d h}=E I(\tan (\theta)) \approx E I \theta(h)=\int_{0}^{h} M(h) d h+C_{1} \\
& E I y=\int_{0}^{h} d h \int_{0}^{h} M(h) d h+C_{1} h+C_{2}
\end{aligned}
$$

By solving the integral equation (4) in the length of wall and the establishment of boundary conditions, the maximum displacement in the slice force point and $\theta_{b}$ in height $b$ from the top of wall are calculated using equations of (5) and (6). Border conditions in equation (4) is inserting displacement and zero slope in wall base.

$y_{b}=\frac{P a^{3}}{3 E I}$

$\theta_{b}=\frac{P a^{2}}{2 E I}$

By substituting equations (5) and (6) in equation (1), we can calculate displacement at the top of the wall under pressure $P_{i}$, using equation (7).

$$
y_{c}=\frac{P a^{2}}{6 E I}(2 a+3 b)
$$

Considering the principle of superposition, we can calculate displacement obtained of each $P_{i}$ and finally calculate total wall displacement based on equation (8).

$y_{1}=\sum_{i=1}^{n} \frac{P a^{2}}{6 E I}(2 a+3 b)$

Displacement obtained by equation (8) relates to immediate displacement. In the shields during the loading and to reach the yield point, modulus of elasticity is fixed and the steel section acts completely both in tension and pressure. Therefore, inertia moment is fixed and section hardness will remain fixed (EI) $\left(4.85^{*} 10^{\wedge} 5 \mathrm{kN} . \mathrm{m} 2 / \mathrm{m}\right)$. However, in reinforced concrete sections, modulus of elasticity and inertia moment will change during the loading due to fraction. Inertia moment of the concrete section is of great importance proportionate to load change and in the wall length. In this case, moment of inertia will change within the elastic moment of inertia $\left(\mathrm{I}_{\mathrm{g}}\right)$ and elasto plastic moment of inertia $\left(\mathrm{I}_{\mathrm{ep}}\right)$. To calculate critical displacement, we can use elasto plastic moment of inertia. In case of using reinforced concrete walls, walls must be designed for longitudinal bars $\left(A_{s}\right)$. The amount of consumed bars in concrete wall is influential in calculating inertia moment, and finally it is influential in the wall displacement. However, due to determination of critical displacement, we can use minimum bar based on equation (9). In addition, elasticity modulus of bar $\left(\mathrm{E}_{\mathrm{s}}\right)$ is influential in the wall displacement, and its effect on inertia moment was considered.

$$
\rho=\frac{A_{s}}{A_{c}} \cong .0015
$$

To calculate modulus of elasticity in concrete walls based on regulations of ACI 318-05, we can use equation (10).

$$
E_{C}=4700 \sqrt{f_{c}^{\prime}}
$$

In concrete sections, in addition to immediate displacement, longterm displacement is also important in a way that long-term displacement increases two times of immediate displacement. In order to calculate long-term displacement, we can use equation (11). Calculation of coefficient $\square$ depends on time that in the most critical state is considered 2 .

$y_{2}=\lambda_{1} y_{1}$

Total displacement of wall in the most critical state is the sum of immediate and long-term displacements, calculated based on equation (12).

$y_{\text {sum }}=y_{1}+y_{2}$

\section{Investigation of the Proposed Method Re- sults Considering Pseudo-Static Effect Owhen Soil Is Unreinforced}

The analyses conducted on unreinforced soils are divided into two main groups. In the first group, we investigated the displacement distribution in the wall height, and we investigated the maximum

\begin{tabular}{|c|c|}
\hline Height of wall (m) & $5-10 \mathrm{~m}$ \\
\hline $\begin{array}{l}\text { Friction angle between wall and backfill } \\
\operatorname{soil}\left(\square^{\circ}\right)\end{array}$ & 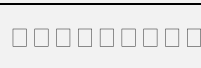 \\
\hline Soil density ( $\square$ ) & $16-22 \mathrm{kN} / \mathrm{m} 3$ \\
\hline Soil cohesion (C) & $0-20 \mathrm{kN} / \mathrm{m} 2$ \\
\hline
\end{tabular}
displacement variations and top of wall displacement versus horizontal acceleration coefficient in the second group of analyses. In each group, seven analyses were conducted based on specifications of Table (3).

Table 3: Characteristics of used wall and soil in analyses for unreinforced soils 


\begin{tabular}{|c|c|}
\hline Internal angle of soil friction $\square \square^{\square}$ ) & $25^{\circ}-45^{\circ}$ \\
\hline Horizontal seismic coefficient,kh (dimensionles) & $0-0.3$ \\
\hline Vertical seismic coefficient,kv (dimensionless) & $0 / 3 \mathrm{kh}-4 / 3 \mathrm{kh}$ \\
\hline Wall thickness(d) & $20-40 \mathrm{~mm}$ \\
\hline
\end{tabular}

In the first and second set of analyses, the distribution of displacement in the height of wall is done by comparing the coefficient of horizontal and vertical acceleration. To increase the accuracy of the results, 1000 horizontal slices were used in results. As According to Figure 3, increase in the horizontal acceleration coefficient, wall displacement increases, which is in contrast with the vertical acceleration coefficient. This displacement is bulging type. If the coefficient of vertical acceleration is zero, overturning deformation occurs, and if the coefficient of vertical acceleration is zero bulging occurs. As the horizontal acceleration coefficient increases, the displacement moves toward top of the wall. An increase in vertical acceleration coefficient moves the maximum displacement towards the wall base. If the coefficient of vertical acceleration equals the coefficient of horizontal acceleration, the top of the wall displacement moves towards the soil.

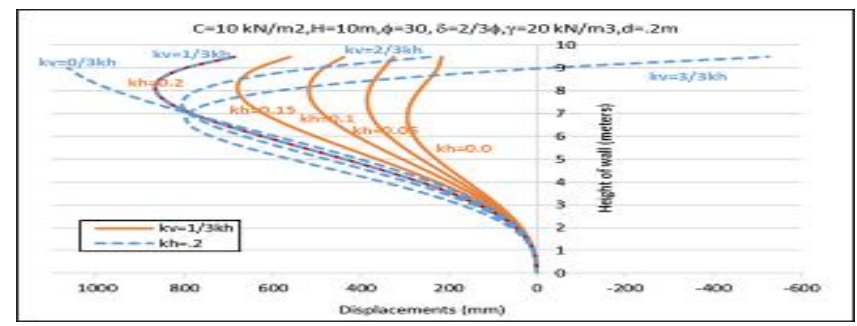

Figure 3: Displacement distribution in wall height by comparing horizontal and vertical acceleration coefficient in unreinforced soil

According to Figure 4, the third to fifth series of analyses discuss the impact of internal friction angle, wall thickness, and the angle of friction between the soil and wall. The results suggest that increasing internal friction angle, wall thickness, and the angle of friction between soil and wall reduces wall displacement. All deformations are of bulging type. Increasing the friction angle between the wall and soil reduces the maximum displacement difference and displacement of the top of the wall.

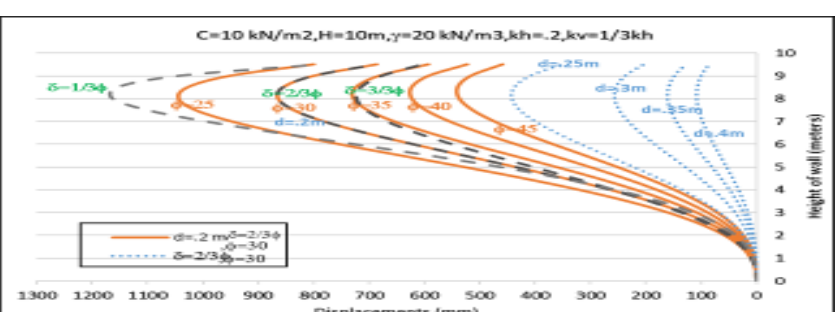

Figure 4: Displacement distribution in wall height by comparing internal friction angle, friction angle of soil, wall, and wall thickness in unreinforced soil

In the sixth and seventh series of analyses, the impact of soil cohesion and specific weight is studied. Increase of cohesion decreases wall displacement, and the increase of specific weight increases wall displacement. In these analyses, all deformations are of bulging type. Also increase of cohesion moves the maximum displacement towards wall base. The results are shown in Figure 5.

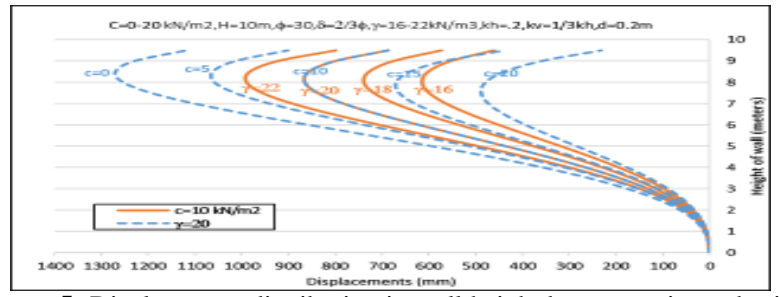

Figure 5: Displacement distribution in wall height by comparing cohesion and soil specific weight in unreinforced soil
In the first and second series of the second group of analyses, the impact of wall thickness and angle of internal friction are studied and (Figures 6 and 7). The results showed that increase in horizontal acceleration coefficient increased of top of the wall displacement and the wall maximum displacement. Also, increase in wall thickness and angle of internal friction reduced the displacement.
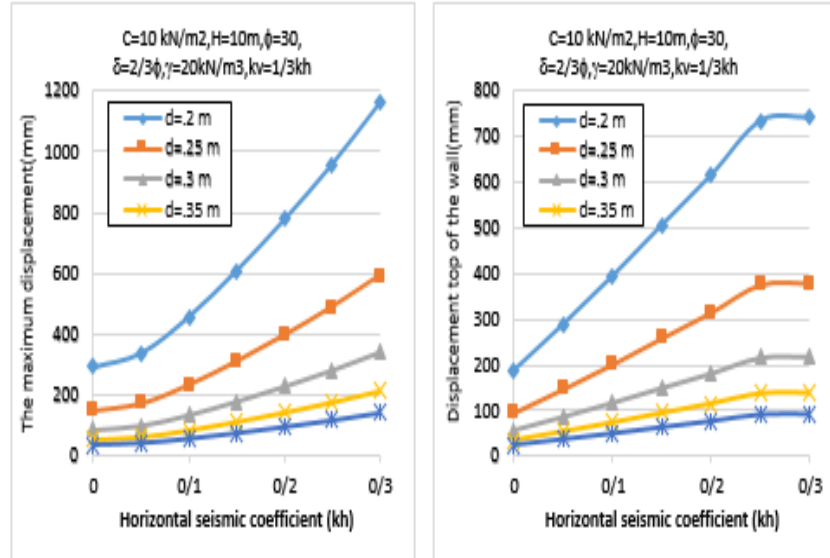

Figure 6: Variations of maximum wall displacement and top of the wall displacement to horizontal acceleration coefficient comparing concrete wall thickness
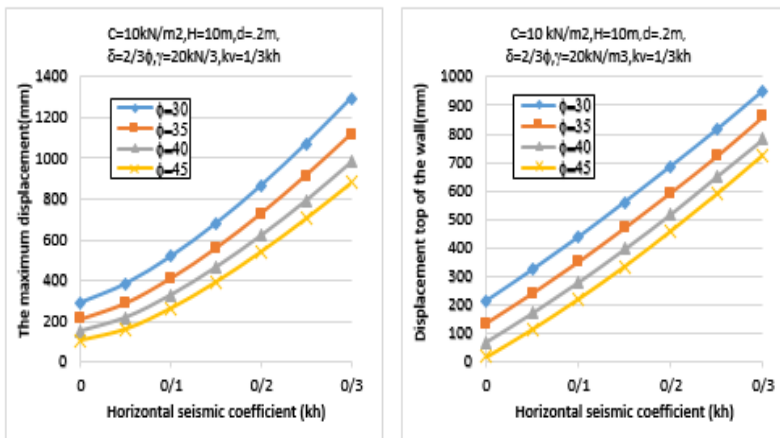

Figure 7: Variations of maximum wall displacement and top of the wall displacement to horizontal acceleration coefficient comparing internal friction angle

According to Figure 8 in the third series of analyses, increase in the horizontal acceleration coefficient increases the maximum wall displacement, and increase in the horizontal acceleration coefficient at $\mathrm{kv}=0, \mathrm{kv}=1 / 3 \mathrm{kh}$ increases the linear displacement of the top of the wall. However, vertical acceleration coefficient of larger than $2 / 3 \mathrm{kh}$, the chart would have a descending trend. Also, increase of the vertical acceleration coefficient reduces displacement in all cases.

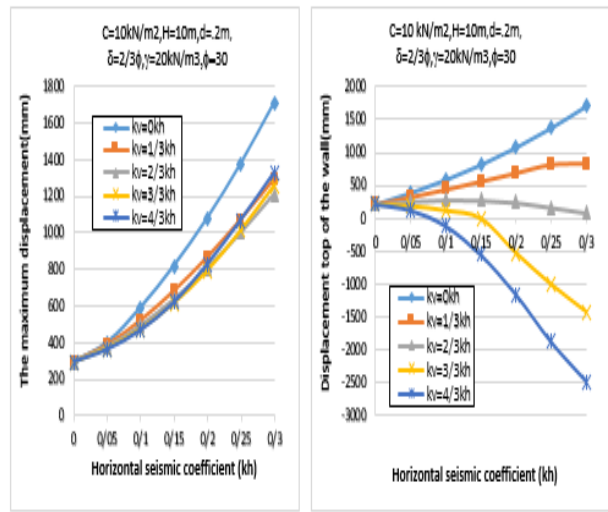

Figure 8: Variations of maximum wall displacement and top of the wall displacement to horizontal acceleration coefficient comparing vertical acceleration coefficient 
In the fourth and fifth series of analyses, the effect of the friction angle between the wall and soil and cohesion is studied. Based on Figures 9 and 10, increase of pseudo-static (kh) horizontal acceleration coefficient increases the top of the wall displacement and maximum displacement of wall. Also, increase in the friction angle between the wall and soil and cohesion reduces the displacement.
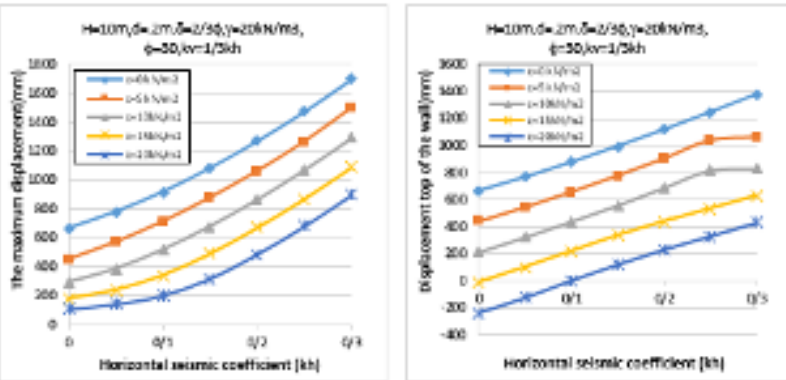

Figure 9: Variations of maximum wall displacement and top of the wal displacement to horizontal acceleration coefficient comparing unreinforced soil cohesion
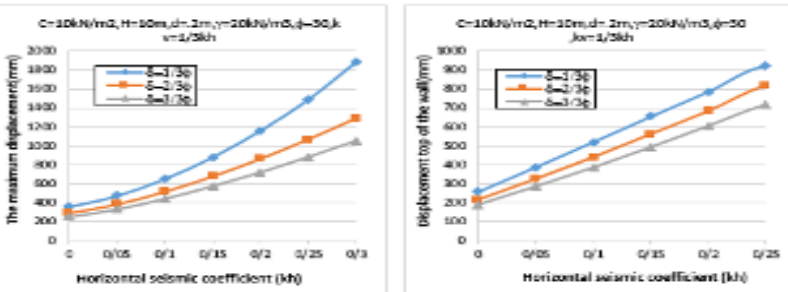

Figure 10: Variations of wall maximum displacement and top of wall displacement to horizontal acceleration coefficient comparing the friction angle between wall and soil

In the sixth and seventh series of analyses, the effect of soil specific weight and height of the wall are discussed. According to Figures (11) and (12), the increase of the horizontal acceleration coefficient increases the top of the wall displacement and wall maximum displacement. Increase of the specific weight and height of the wall in both charts increases the chart variations with the same slope.
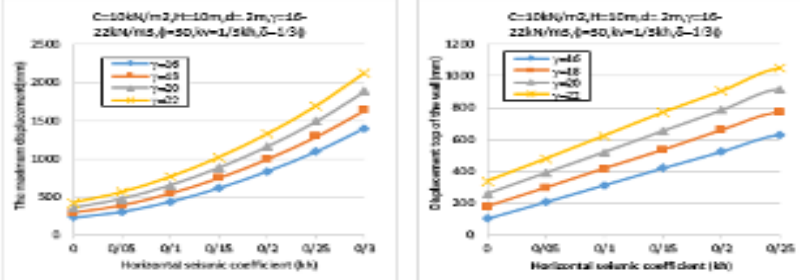

Figure 11: Variations of wall maximum displacement and top of wall displacement to horizontal acceleration coefficient comparing soil specific weight
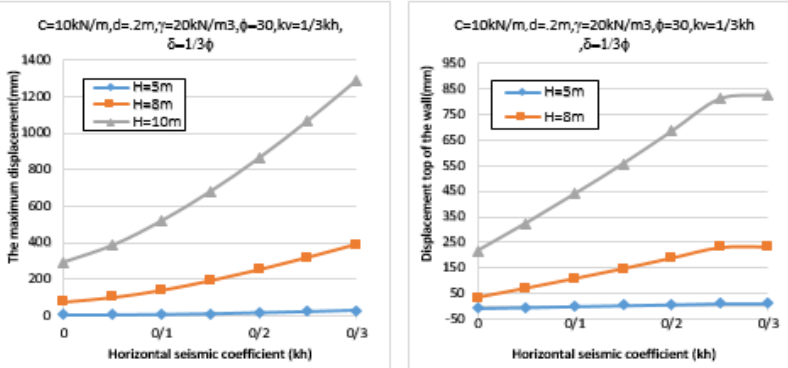

Figure 12: Variations of wall maximum displacement and top of wall displacement to horizontal acceleration coefficient comparing wall height

\section{Determining Critical Rupture Wedge Angle of Displacement in Unreinforced Soils}

In this method, in addition to the rupture wedge angle that measures the maximum pressure exerted on the wall, there is also the rupture wedge angle for which the greatest displacement occurs at the top of the wall, showing that the pressure of rupture wedge angle on the wall $(\square \mathrm{p})$ is different from the rupture wedge angle of the wall displacement $\left(\square_{\square} \square\right.$, which is the most important achievement of this research. The results suggest that increasing the internal friction angle increases the linear rupture wedge angle of displacement. Also increase of the horizontal acceleration coefficient reduces the rupture wedge angle of displacement. Figure 13 presents a new formulation to calculate the rupture wedge angle of displacement.

$$
\beta^{\circ}=\frac{\phi^{\circ}}{2}+\frac{\pi}{4}-(78.4 \times k h)
$$

\section{Proposed Method to Determine Retaining Wall Displacement in Reinforced Soils}

The analyses conducted in reinforced soils are divided into two main groups. In the first group, we investigated the displacement distribution in the wall height, and we investigated the maximum displacement variations versus horizontal acceleration coefficient in the second group of analyses, in the first group, two analyses and in the second group, four analyses were conducted (Table 4).

Table 4: Soil and wall characteristics used in analyses of reinforced soils

\begin{tabular}{|c|c|}
\hline Height of wall (m) & $10 \mathrm{~m}$ \\
\hline $\begin{array}{c}\text { Friction angle between wall and backfill } \\
\text { soil( } \square^{\circ} \text { ) }\end{array}$ & $\square \square \square \square \square \square \square$ \\
\hline Soil density ( $\square$ ) & $20 \mathrm{kN} / \mathrm{m} 3$ \\
\hline Soil cohesion (C) & $0-20 \mathrm{kN} / \mathrm{m} 2$ \\
\hline Internal angle of soil friction $\left.\square \square^{\square}\right)$ & $30^{\circ}-45^{\circ}$ \\
\hline $\begin{array}{c}\text { Horizontal seismic coefficient,kh (dimension- } \\
\text { less) }\end{array}$ & -0.2 up to 0.2 \\
\hline Vertical seismic coefficient,kv (dimensionless) & $-4 / 3 \mathrm{kh}$ up to $4 / 3 \mathrm{kh}$ \\
\hline Wall thickness(d) & $20 \mathrm{~mm}$ \\
\hline Vertical spacing of reinforcements (Sv) & $0.5 \mathrm{~m}-2 \mathrm{~m}$ \\
\hline
\end{tabular}

The results show that (Figure 14) the increase of vertical acceleration coefficient reduces the wall displacement. In these analyses, all deformations are in of overturning type. In these analyses, the opposite direction of vertical seismic force was used. It is shown that seismic force that is in opposite direction of presumption that has greater impact than the presumption state. Increase of vertical seismic acceleration coefficient in the opposite direction increases the wall displacement.

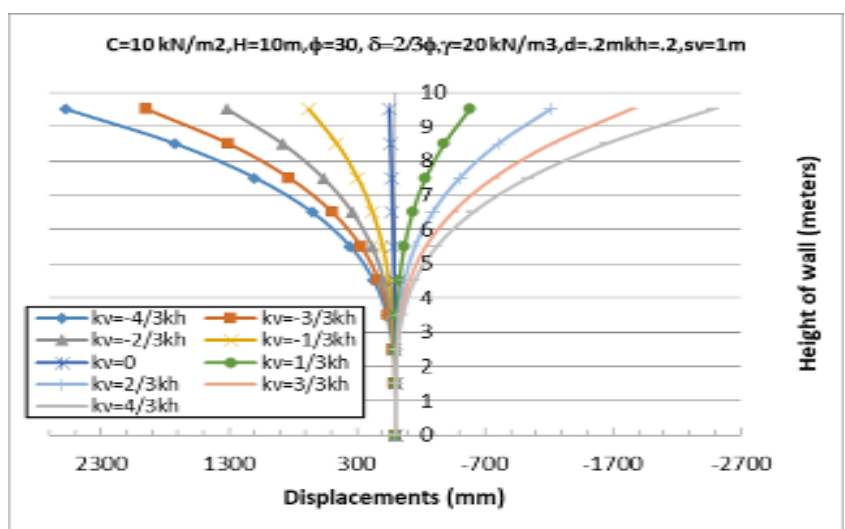

Figure 20: The impact of vertical acceleration coefficient on displacement of reinforced walls 
According to Figure 15, increase in the number of reinforcements reduces the wall displacement. In this set of analyses, 5, 10, 15 , and 20 reinforcements were used. It reduced wall displacement $55.78 \%, 86.6 \%, 93.6 \%$, and $96.3 \%$ compared to unreinforced state. Increase in the number of reinforcements had no impact on the type of deformation and all of them are of overturning type.

$\mathrm{C}=10 \mathrm{kN} / \mathrm{m} 2, \mathrm{H}=10 \mathrm{~m}, \phi=30, \delta=23 \phi, \gamma=20 \mathrm{kN} / \mathrm{m} 3, \mathrm{~d}=.2 \mathrm{~m}, \mathrm{kv}=0, \mathrm{kh}=.2$

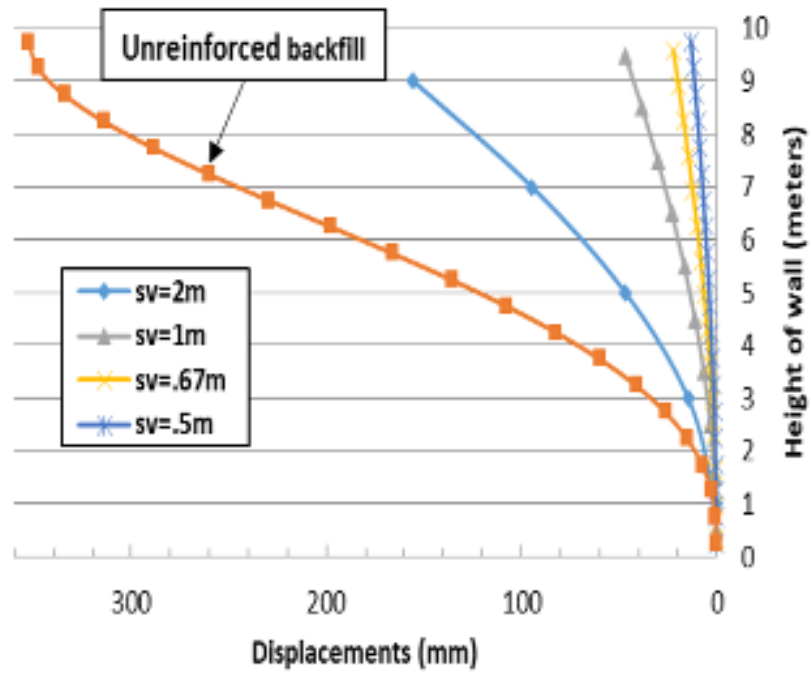

Figure 20: The impact of the number of reinforcements on wall displacement of reinforced soils

To assess earthquake-reciprocating force, the impact of negative coefficients of horizontal acceleration is considered in this analysis (Figure 16). Increase in horizontal acceleration coefficient increases the wall displacement. As it was observed in all of the previous analyses, increase of internal friction angle decreases the linear changes.

$\mathrm{C}=10 \mathrm{kN} / \mathrm{m} 2, \mathrm{H}=10 \mathrm{~m}, \mathrm{~d}=.2 \mathrm{~m}, \delta=2 / 3 \phi, \gamma=20 \mathrm{kN} / \mathrm{m} 3, \mathrm{kv}=0, \mathrm{sv}=1 \mathrm{~m}$

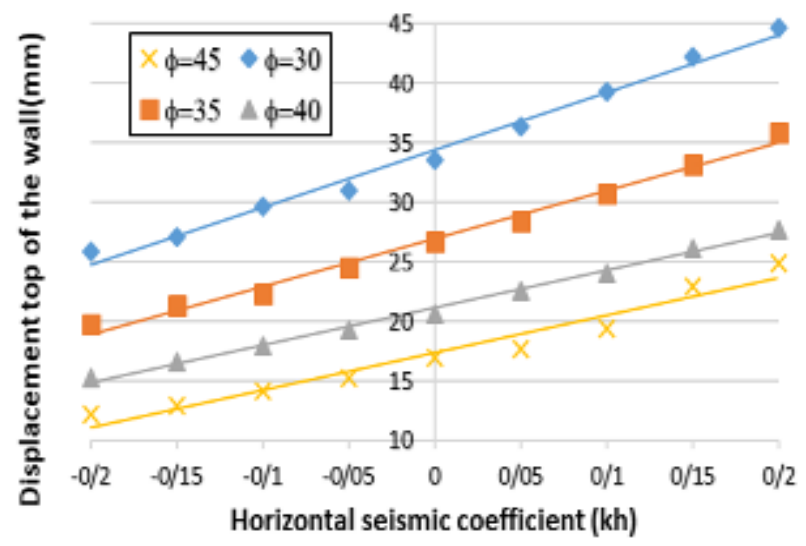

Figure 16: Variations of horizontal acceleration coefficient versus wall displacement of reinforced soil for various values of internal friction angle

Increase of horizontal acceleration coefficient increases the wall displacement (Figure 17). Increase of soil cohesion reduces the wall displacement, but cohesion effect increases with increase in the horizontal acceleration coefficient so as in the coefficient of $\mathrm{kh}=0.05$ only $2.6 \%$ of wall displacement is reduced which is negligible, while in $\mathrm{kh}=0.2$ it is reduced $13.3 \%$, indicating that the increase of the impact of cohesion is high in the horizontal acceleration coefficients. $\phi=30, \mathrm{H}=10 \mathrm{~m}, \mathrm{~d}=2 \mathrm{~m}, \delta=2 / 3 \phi, \gamma=20 \mathrm{kN} / \mathrm{m} 3, \mathrm{kv}=0,5 \mathrm{v}=1 \mathrm{~m}$

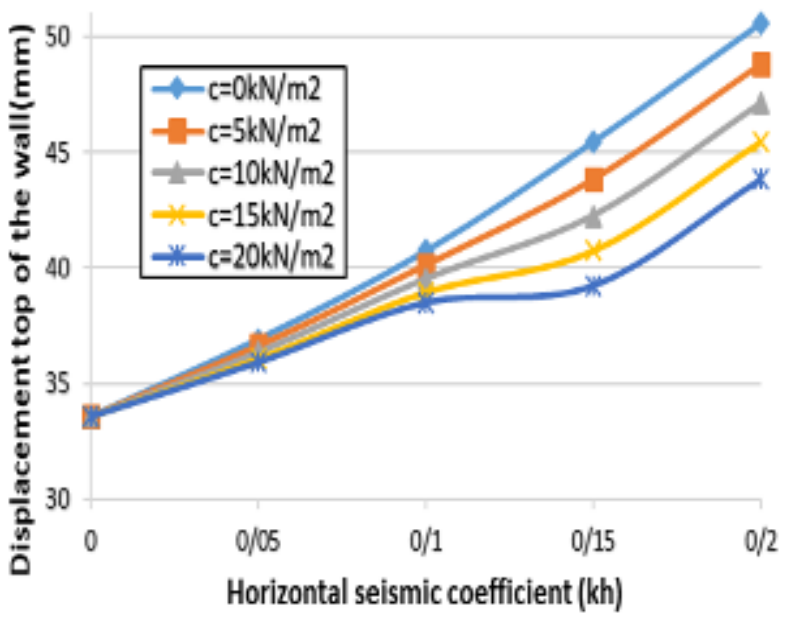

Figure 17: Variations of horizontal acceleration coefficients versus reinforced soil wall displacement for various vales of soil cohesion

According to Figure 18, increase in the horizontal acceleration coefficient increases wall displacement in negative vertical acceleration coefficient. However, in the case of positive vertical acceleration coefficient, displacement variations and horizontal acceleration coefficient are descending. Increase in the horizontal acceleration coefficient and the number of reinforcements increase the wall displacement (Figure 19).

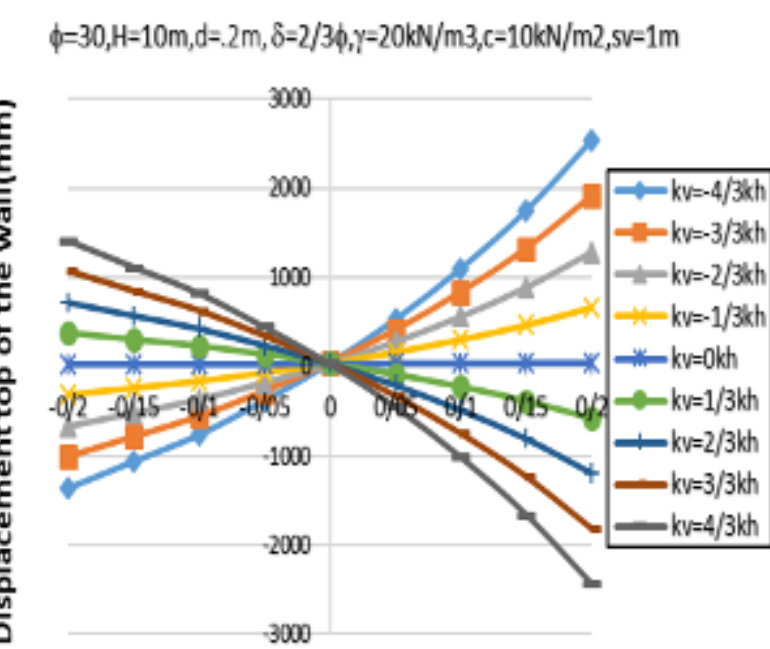

\section{Horizontal seismic coefficient (kh)}

Figure 18: Variations of horizontal acceleration coefficient versus reinforced soil wall displacement for various values of pseudo-static vertical acceleration coefficient

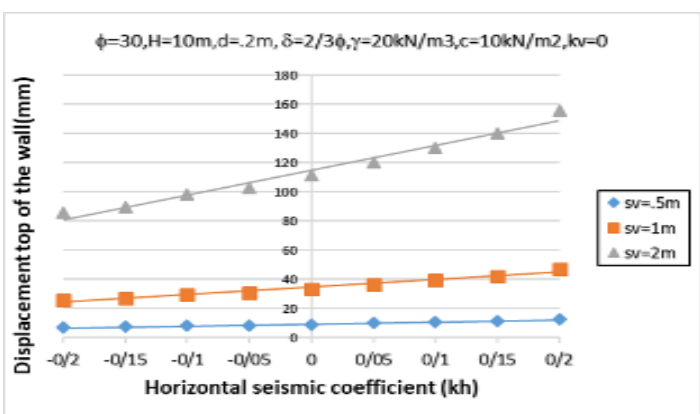

Figure 19: Variations of horizontal acceleration coefficient versus reinforced soil wall displacement for the number of reinforcements 


\section{Comparing the Proposed Method Results with Numerical and Other Researchers' Re- sults}

Various methods have been introduced so far to examine the wall displacements of reinforced and unreinforced walls. However, each of these methods had been designed for particular situations and had their own shortcomings. Results were presented in this study using limit equilibrium principles and assumptions of horizontal slices method for the wall in cohesive frictional reinforced soil. In this section, results obtained from the proposed method were compared with the results of previous researchers in equal condition.

To validate the equations, element numerical methods were used by Abaqus software. This model has been drawn in 3D and the specifications of the concrete wall and backfill have been homogenized. In the soil specifications, plastic behavior of soil was used with Mohr-Coulomb model, and in meshing, Tri type (triangular element type) was used.

In Figure 20, four analyses with horizontal acceleration coefficient variations are drawn and in Figure 21, four other analyses with internal friction angle variations are drawn.

Abaqus software presents the immediate displacement in the concrete wall. The obtained results suggest that there is good convergence between immediate analytical results and numerical results.

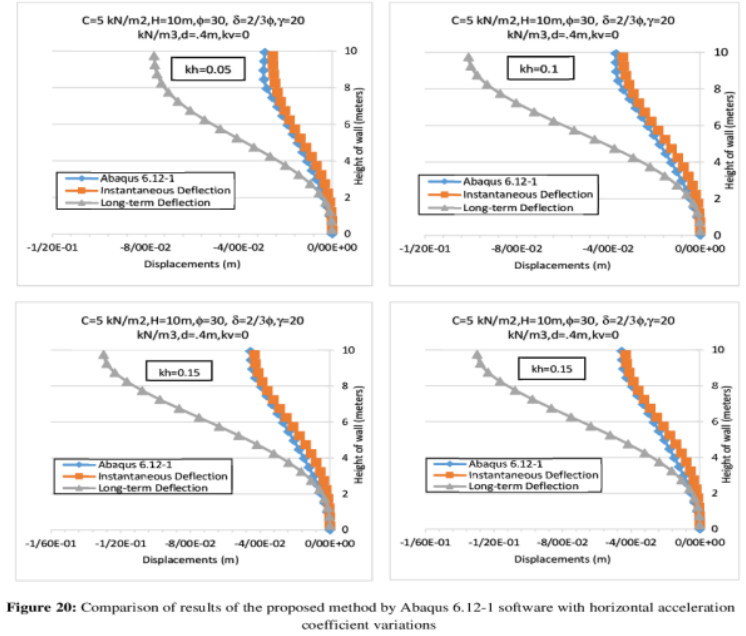

Figure 20: Comparison of results of the proposed method by Abaqus 6.121 software with horizontal acceleration coefficient variations

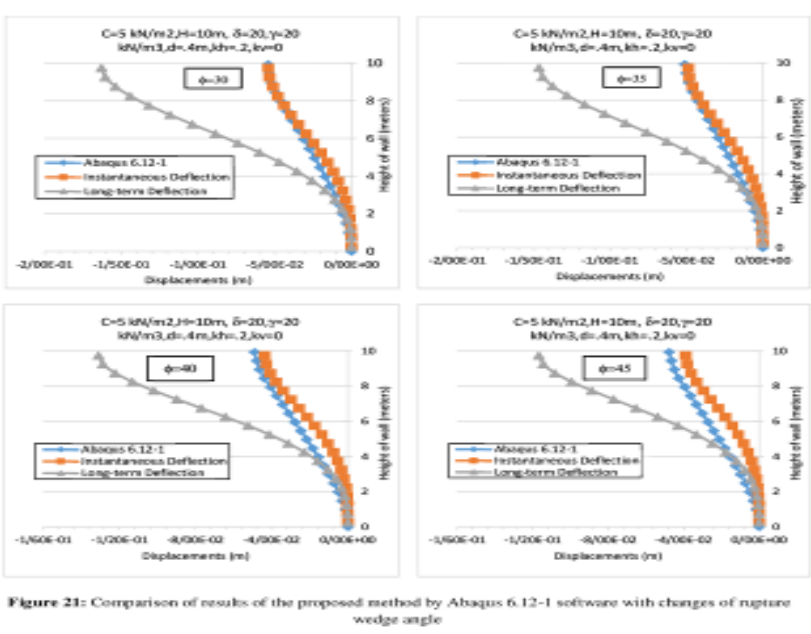

Figure 21: Comparison of results of the proposed method by Abaqus 6.121 software with changes of rupture wedge angle
Table 5 compares the results of the proposed method by Euro-code 8; in Table $6\left(\square_{\mathrm{p}}\right)$ and $\square \square_{\square} \square \square$ results are compared with other studies stating that the maximum displacement in $\square \square_{\square} \square \square$ is more than $\square(\square \mathrm{p})$.

Table 5: Comparing the proposed method displacement with other researchers for unreinforced soil wall

\begin{tabular}{|c|c|c|c|c|c|c|}
\hline Method & $\begin{array}{c}\text { Proposed } \\
\text { method }\end{array}$ & $\begin{array}{c}\text { Ghanbari\& } \\
\text { Ahmadabadi(2010) }\end{array}$ & $\begin{array}{l}\text { Mononobe- } \\
\text { Okabe(1929) }\end{array}$ & $\begin{array}{l}\text { Steedman- } \\
\text { Zeng }(1990)\end{array}$ & $\begin{array}{l}\text { Richards\& } \\
\text { Elms(1979) }\end{array}$ & $\begin{array}{l}\text { Euro Code } \\
8\end{array}$ \\
\hline $\begin{array}{c}\text { Seismic active earth } \\
\text { pressure. } P(\mathrm{kN} / \mathrm{m})\end{array}$ & 143.598 & 143.35 & 145.16 & 141.24 & 100.92 & 100.92 \\
\hline $\begin{array}{l}\text { P.eaz of } P \text { frome } \\
\text { base(m) }\end{array}$ & . 9 ast & .98 & 2.72 & 2 & 2.33 & 2.33 \\
\hline Displacement $(\mathrm{mm})$ & 93.71 & (-1) & - & |----- & 100 & 100 \\
\hline
\end{tabular}

Table 6: Comparing the rupture wedge angle in the proposed method with other researchers methods for unreinforced soil wall

\begin{tabular}{|c|c|c|c|c|c|c|c|c|c|c|c|c|c|c|c|}
\hline \multicolumn{16}{|c|}{$\mathrm{H}=10 \mathrm{~m}, \delta=2 / 3 \phi, \gamma_{\mathrm{s}}=20 \mathrm{kN} / \mathrm{m}^{3}, \gamma_{\mathrm{c}}=24 \mathrm{kN} / \mathrm{m}^{3}$} \\
\hline \multicolumn{16}{|c|}{$A\left(\beta_{5}\right)=$ Proposed method } \\
\hline \multicolumn{16}{|c|}{$\mathrm{B}\left(\beta_{\mathrm{p}}\right)=$ Proposed method } \\
\hline \multicolumn{16}{|c|}{$C\left(\beta_{p}\right)=$ Mojalla and Ghanbari(2012) } \\
\hline \multicolumn{16}{|c|}{$D\left(\beta_{p}\right)=$ Zarrabi-Kashani $(1979)$} \\
\hline \multicolumn{4}{|c|}{$\mathrm{kh}=0.1, \phi=30^{\circ}$} & \multicolumn{4}{|c|}{$\mathrm{kh}=0.2, \phi=32^{\circ}$} & \multicolumn{4}{|c|}{$\mathrm{kh}=0.25, \phi=34^{\circ}$} & \multicolumn{4}{|c|}{$\mathrm{kh}=0.3, \phi=36^{\circ}$} \\
\hline A & $B$ & $\mathrm{c}$ & $D$ & A & B & $\mathrm{c}$ & D & A & $B$ & c & D & A & $B$ & $\mathrm{c}$ & D \\
\hline 51.6 & 50.35 & 50.5 & 50.53 & 40.5 & 45.45 & 45.8 & 46.10 & 36.2 & \begin{tabular}{|l|l}
43.6 & \\
\end{tabular} & 44.2 & 44.78 & 32.6 & 41.7 & 42.6 & 43.51 \\
\hline
\end{tabular}

To validate the presented equations at reinforced soil wall, the proposed method was compared with numerical method using Abaqus software. In this software, we can insert reinforcement parameters and their length. Change in the length of reinforcements and their characteristics change the results. The proposed method is an analytical method based on limit analysis that records the reinforcements' forces and wall displacement in the rupture, and it does not depend on the type and length of reinforcements. This has resulted in difference between results of numeric method and analytical method (Table 5).

Table 7: Comparing the proposed method results with Abaqus 6.12-1 for reinforced soil wall

\begin{tabular}{|c|c|c|c|c|c|c|c|c|c|c|c|c|c|c|}
\hline \multicolumn{15}{|c|}{$\mathrm{C}=10 \mathrm{kN} / \mathrm{m} 2, \mathrm{H}=10 \mathrm{~m}, \delta=20^{\circ}, \gamma=20 \mathrm{kN} / \mathrm{m} 3, \mathrm{~d}=, 4 \mathrm{~m}, \mathrm{kv}=0, \mathrm{~Sv}=1 \mathrm{~m}, \phi=30^{\circ}$} \\
\hline \multirow{2}{*}{\multicolumn{15}{|c|}{$\begin{array}{c}A(\mathrm{~mm})=\text { Proposed method (Instantaneous Deflection) } \\
\mathrm{B}(\mathrm{mm})=\text { Proposed method(Long-term Deflection) } \\
\text { C(mm) }=\text { Abaqus 6.12-1 }\end{array}$}} \\
\hline & & & & & & & & & & & & & & \\
\hline \multicolumn{3}{|c|}{$\mathrm{kh}=0$} & \multicolumn{3}{|c|}{$\mathrm{kh}=0.05$} & \multicolumn{3}{|c|}{$\mathrm{kh}=0.1$} & \multicolumn{3}{|c|}{$\mathrm{kh}=0.15$} & \multicolumn{3}{|c|}{$\mathrm{k}_{1}=0.2$} \\
\hline A & B & C & A & B & $\mathrm{C}$ & A & B & $\mathrm{C}$ & A & B & $\mathrm{C}$ & A & B & $\mathrm{C}$ \\
\hline 1.39 & 4.19 & 1.41 & 1.51 & 4.54 & 2.37 & 1.63 & 4.90 & 3.38 & 1.76 & 5.28 & 4.41 & 1.96 & 5.88 & 5.54 \\
\hline
\end{tabular}

\section{Conclusion}

Based on the studies presented in this paper, the following results are obtained:

In this method, it is possible to calculate the maximum displacement, draw displacement modes, and determine the critical rupture wedge angle with displacement priority. A benefit of this procedure is to consider all soil parameters such as cohesion, friction angle between soil and wall, and internal friction angle of the soil. Different specifications of wall such as concrete stiffness, modulus of elasticity of concrete, concrete cracking, wall thickness, and reinforcement steel specifications are considered that none of the previous methods enjoys this general state in seismic conditions. Parameters of quasi-static vertical and horizontal acceleration coefficient in both directions are considered in the formulation. In unreinforced soil, 14 series of analyses were conducted, showing that, in $\mathrm{kv}=0$, deformation is of overturning type, and in other states, deformation is of bulging type. Change of the angle of internal friction and cohesion and other soil characteristics and wall thickness have no affect on the type of deformation, but change in 
earthquake acceleration coefficients changes the maximum displacement at wall height.

In unreinforced soils, increase of wall thickness, angle of internal friction, cohesion, angle of wall friction between the soil and wall, and soil specific weight reduce wall displacement. However, the increase in quasi-static coefficient of horizontal acceleration and vertical acceleration coefficient $\mathrm{kv}=0$ and $\mathrm{kv}=1 / 3 \mathrm{kh}$ increases the wall displacement.

A new formulation was provided to calculate the rupture wedge angle of displacement. The results show that the rupture wedge angle of the pressure on wall ( $\square$ p) is different from the rupture wedge angle of wall displacement $(\square \square \square \square \square$ The results suggest that increasing internal friction angle increases linearly the rupture wedge angle of displacement. Also increase of the quasi-static horizontal acceleration coefficient reduces the rupture wedge angle of displacement.

In reinforced soils, eight series of analyses were conducted, showing that all deformations are of overturning type. Increase in the angle of internal friction, cohesion, the friction angle between soil and wall, and the number of reinforcements reduce wall displacement. However, the increase in quasi-static coefficient of horizontal acceleration and vertical seismic acceleration coefficient in the opposite direction of the presumption increases the wall displacement.

Comparison of the results of the present method with numerical methods and Euro Code 8 indicates that there is an appropriate convergence between immediate analytical results and numerical analyses.

\section{References}

[1]. ABAQUS 6.10. 2010, Documentation, Dassault Systemes Simulia Corp., Providence, RI, USA.

[2]. ACI 318-05, Building Code Requirements for Structural Concrete and Commentary - ACI 318R-05, American Concrete Institute, Farming Hills, MI, USA, 2005.

[3]. Ahmadabadi, M. and Ghanbari, A., 2009. New procedure for active earth pressure calculation in retaining walls with reinforced cohesive-frictional backfill. Geotextiles and Geomembranes 27 (2009) $456-463$.

[4]. Athanasopoulos, A-Zekkos., Lamote, G., Athanasopoulos, G.A. (2012), "Use of EPS geofoam compressible inclusions for reducing the earthquake effects on yielding earth retaining structures," Soil Dynamics and Earthquake Engineering 41, pp 59-71.

[5]. Azad, A., Yasrobi, S., Pak, A., 2008. Seismic active earth pressure distribution behind rigid retaining walls. Soil Dynamics and Earthquake Engineering. 28(5), 365-375.

[6]. Bhattacharjee, A., Krishna, A. Murali. (2010), "Numerical modelling of rigid faced reinforced soil walls under seismic shaking, " Indian Geotechnical Conference.

[7]. Bourgeois, E., Soyez, L., Le Kouby, A. (2011), "Experimental and numerical study of the behavior of a reinforced-earth wall subjected to a local load,". Computers and Geotechnics 38 (2011) 515-525.

[8]. Euro code 8, EN 1998. "Design provisions for earthquake resistance of structures".

[9]. Fakher, A.,Nouri,H.,Shahgholi, M.,(2002)."Limit equilibrium in reinforced soil walls subjected to seismic loads".In:Proceedings of the third Iranian International Confrence on Geotachnical Engineering and soil Mechanics, Tehran Vol.3,281-286.

[10]. Ghanbari, A. and Ahmadabadi, M. (2010), "Pseudo-Dynamic Active Earth Pressure Analysis of Inclined Retaining Walls Using Horizontal Slices Method" ,Scientia Iranica Volume 17, Issue 2, 2010,ISSN: 1026-3098

[11]. Ghanbari, A. and Ahmadabadi, M. (2010)," New analytical procedure for seismic analysis of reinforced retaining wall with cohesive - frictional backfill"Geosynthetics International, 2010, 17, No. 6,364-379

[12]. Ghanbari, A. and Ahmadabadi, M. (2010),"Active earth pressure on inclined retaining walls in static and seismic conditions" International Journal of Civil Engineering, Volume 8, Number 2 (6-2010).

[13]. Ghanbari, A., Khalilpasha, A., Sabermahani, M., Heydari, B. (2013), "An analytical technique for estimation of seismic displacements in reinforced slopes based on horizontal slices method
(HSM)," Geomechanics and Engineering, Vol. 5, No. 2 (2013) 143164.

[14]. Matlock, H., and Reese, L. C (1960)."Generalized Solution for Laterally Loaded Piles," Journal of the Soil Mechanics and Foundations Division, American Society of Civil Engineers, Vol. 86, No.SM5,Part I, pp. 63-91

[15]. Mojallal, M; Ghanbari, A.(2012),'Prediction of seismic displacements in gravity retaining walls based on limit analysis approach" Structural Engineering and Mechanics, Volume 42, Issue 2, 2012, pp.247-267.

[16]. Mononobe N, Matsuo H., 1929. On the determination of earth pressure during earthquakes. In: Proceeding of the World Engineering Congress, vol. 9, Tokyo, 179-87.

[17]. Nouri, H., Fakher, A., Jones, C.J.F.P., 2006. Development of horizontal slices method for seismic stability analysis of reinforced slopes and walls. Geotextiles and Geomembranes 24, 175-187.

[18]. Nouri, H., Fakher, A., Jones, C.J.F.P., 2008. Evaluating the effects of the magnitude and amplification of pseudo-static acceleration on reinforced soil slopes and walls using the limit equilibrium horizontal slices method. Geotextiles and Geomembranes 26(3), 263-278.

[19]. Okabe, S., 1926. General Theory of Earth Pressures, J. Japan Soc. Civil Engineering, 12(1).

[20]. Reddy, G.V.N., Madhav, M.R., Reddy, E.S., 2008. Pseudo-static seismic analysis of reinforced soil wall - effect of oblique displacement. Geotextiles and Geomembranes 26 (5), 393-403.

[21]. Richards, R. and Elms, D. G., Seismic behaviour of gravity retaining walls. J. Geotech. Eng., ASCE, 1979, 105, 449-464.

[22]. Sabermahani, M., Ghalandarzadeh A., Fakher A., 2008. Experimental study on seismic deformation modes of reinforced-soil walls. Geotextiles and Geomembranes 27, 121-136.

[23]. Sakaguchi, M. (1996). "A study of the seismic behavior of geosynthetic reinforced walls in JAPAN," Geosynthetics International, Vol. 3, No.1, 13-30.

[24]. Segrestin, P., 1992. Design of sloped reinforced fill structure, in: Proc. Conference on Retaining Structures, Inst. of Civil Eng., Robinson College, Cambridge, pp. 574-584.

[25]. Shahgholi M, Fakher A, Jones C.J.F.P., 2001. Horizontal slice method of analysis, Geotechnique, 51(10): 881-885.

[26]. Vagneron J. J., Adams B. D., "Reinforced earth retaining walls", J. Soil Mech. Fdns. Div., ASCE, Vol 99 (SM10), Oct., (1973) 958966.

[27]. Yufeng Gao,Shangchuan Yang,Yongxin Wu,Dayong Li,Fei Zhang.,2014.Evaluation of oblique pullout resistance of reinforcements in soil wallsubjected to seismic loads.Geotextiles and $\mathrm{Ge}$ omembranes 42 (2014) 515-524.

[28]. Yu-liang Lin, Wu-ming Leng,Guo-lin Yang,Lian-heng Zhao,Liang Li,Jun-sheng Yang.,2015.Seismic active earth pressure of cohesivefrictional soil on retaining wall based on a slice analysis method. Soil Dynamics and Earthquake Engineering 70 (2015) 133-147.

[29]. Zarrabi-Kashani, K., 1979. Sliding of gravity retaining wall during earthquakes considering vertical accelerations and changing inclination of failure surface, Ms Thesis, Department of Civil Engineering, Massachusetts Institute of Technology, and Cambridge, MA. 